\title{
A sustainable reverse supply chain for customer requirement fulfillment
}

\author{
Reza Khoshnoodi ${ }^{\mathrm{a}}$, Hamed Fazlollahtabar ${ }^{\mathrm{b}, \mathrm{c}^{*}}$ and Iraj Mahdavi ${ }^{\mathrm{a}}$
}

${ }^{a}$ Department of Industrial Engineering, Mazandaran University of Science and Technology, Babol, Iran

${ }^{b}$ Faculty of Industrial Engineering, Iran University of Science and Technology, Tehran, Iran

${ }^{c}$ Niroogostar Energy Optimization Research Group, Tehran, Iran

\section{CHR O N C L E AB S T R A T}

Article history:

Received January 12, 2013

Received in revised format

10 April 2013

Accepted 18 April 2013

Available online

April 202013

Keywords:

Sustainable supply chain

Customer requirement

Clustering

Mathematical programming

\begin{abstract}
In this paper, we study a reverse supply chain consists of three layers of the supply chain including suppliers, producers and customers by considering customers' requirements. In the customer layer, we analyze the customer's data to identify and fulfill their needs by collecting a list of customers' views into consideration. In this case, the proposed model analyzes the customers view in the three areas of transport, production and quality and it uses the coding system for getting customers' opinions. Then, by using the K-means algorithm, which is one of the data analyzing algorithms, the proposed model clusters the data so that similar data enter to the same cluster. The mathematical model is developed for each of the categories and Lingo software package is employed to solve the resulted problem in each category.
\end{abstract}

(C) 2013 Growing Science Ltd. All rights reserved.

\section{Introduction}

Reverse logistic network is considered as part of supply chain and can be defined as "the accurate and timely transmission of materials used and goods haven't been solved through the supply chain to the end consumer of the last unit of the good" (Lee et al., 2009). In other words, reverse logistics is the process of returning and transporting goods and products for alternative purposes such as properly recycling, etc. Design and implementation of reverse logistics network for product returns, inventory, and transportation not only reduce costs but also increases customer loyalty (Lee et al., 2009). According to American Association Reverse Logistics Executive, reverse logistics is defined as “ the process of planning, implementing and controlling the flow of raw materials, semi-manufactured inventories, end products And information to help them in terms of cost, from the point of origin to point of consumption, with the goal of re-creating value or proper disposal" (Lu \& Bostel, 2007). 
Reverse logistics in supply chain starts with returned items; components for recycling or recovery value and collected materials for proper disposal. Reverse logistic firms propose appropriate planning, implementation and control of reverse logistics, which could be divided into three categories:

- Economic factors (direct and indirect),

- Rules and regulations,

- Accountability for environmental sensitivities.

Logistics network design is a strategic decision, which normally involves the nature of the facilities, their capacity, number of products, number of classes in the chain, and it is associated with different facilities. All these issues influence the performance and the performance of their supply chain. Since the construction of the facility or closing costs take relatively a long time, changes in the short run is not possible. In addition, investing in strategic network design decisions, tactical and operational decisions are greater return on investment (Pishvaee et al., 2010).

Product returns are often regarded as a cost of doing business, thereby reverse supply chain management (RSCM) is one of the area of interests, which is becoming popular. In fact, more researchers and managers start to realize that RSCM can provide competitive advantage instead of posing problems if it is being managed effectively (Price-White, 2002).

Some people believe that returned goods are important parts of the supply chain, and report that reverse logistics management could save up to $1-2 \%$ of total revenue. For instance, total processing fees and product value of product returns cost suppliers in the US exceeded $\$ 100$ billion per year during the past decade (Stock et al., 2000). Thus, ignoring the issue of product returns can be very costly. Hewlett Packard product returns used to be treated as a low-level divisional problem the firm realized that the total cost of product returns was equivalent to $2 \%$ of total outbound sales (Guide et al., 2003).

The idea of utilizing used products is indeed not groundbreaking as it has been around for many decades. Recovering used products for remanufacturing and recycling emerged in the 1960's and manufacturers have been specializing in remanufacturing/recycling for their own products (Guide et al., 2003). Recovering values of products traveling upstream is also a familiar research topic, being referred by terminologies such as product recovery, recycling, and closed-loop manufacturing. The newest terminologies for this similar concept emerging during the last few years include closed-loop supply chain, reverse logistics, reverse supply chain, green supply chains, and environmentally responsible manufacturing. Yet, most of this research is highly operations oriented (Dowlashahi, 2000), mainly based on the physical structures of upstream product movements. There is hardly any study that investigates the benefits of RSCM and develops a model/framework to thoroughly examine RSCM practices and its effects (Guide et al. 2003).

There are also few consensuses on the definition of RSCM. The use of the terms such as reverse logistics, reverse supply chain, etc. bears contains various meanings from one study to another. Most importantly, it appears that most research views managing returned products as a problem of product manufacturers. Thus, while forward SCM emphasizes the chain perspective in their research and practice, RSCM demonstrates a clear shortcoming on the chain perspective. Meanwhile, RSCM becomes increasingly important for a number of reasons. The most noticeable is the change in legislation in regard to managing industrial waste. Many industries are specifically required to look at their own products once being disposed, particularly if they contain hazardous materials. Given the rising number of environmentally conscious countries and consumers, legislation can only become stricter. Second, today customers are more educated and demanding, and tend to have less tolerance for imperfect products (Krikke et al. 2004; Avittathur \& Shah 2004). As a result, return policies are 
becoming much more lenient (Guide et al., 2003). Furthermore, wholesalers and retailers also push for more extended return warranties to reduce their own risks.

Manufacturers often have to provide take-back warranties for any unsold, damaged, end-of-season, or obsolete products to sell their products. Shorter product life cycles, frequent new product introductions, product leasing and up-grade options are also among other reasons to increase the volume of reverse flows. It is estimated that customers return $6 \%$ of all retail purchases in the US, which is around $\$ 52$ billion worth of returned goods annually (Tibben-Lembke, 2004). Fourth, companies, that incorporate remanufacturing/recycling in their business model such as Xerox and Kodak and even invest in technologies that allow them to do so effectively, find it crucial to be able to recover and sort their used products efficiently. Finally, new business models such as catalogue and mail order, and especially e-business affect product flows forward and backward significantly (DiMaggio 2000; Krikke et al., 2004). Wehkam, a large mail order company in the Netherlands has $28 \%$ of product returns, or about 10,000 items per day (Van Nunen \& Zuidwijk, 2004). The Home Shopping Network ships around 32 million packages each year, of which 6.4 million are returned, making it a real challenge to keep track of both forward and reverse flows of products and payments (Morton, 2003). On average, 20\% of products sold by e-retailers are returned and the figure could be as high as $35 \%$ for certain products such as clothing (Trebilcock, 2002).

Due to such changes in the operational environment, companies find themselves having to great deal with an increasing number of unwanted products, used, end-of-life, defective, or obsolete materials. Yet managing this problem is not easy given the novelty of problem recognition and its unpredictability in nature (Blackburn et al., 2004). Product return flows are characterized as uncertain and unpredictable in terms of quantity, timing, type, and status, making it very challenging to handle (Minner, 2001; van Nunen \& Zuidwijk, 2004).

RSCM problem represented as a time consuming and costly problem, while yielding few benefits (Guide et al., 2003). A new way of looking at the whole product return process is needed to better understand and handle the issue. This paper intends to provide a thorough literature review on the topic of RSCM and develop a framework to research the practices and benefits of RSCM in the future. The literature review aims at reflecting the progress as well as shortfalls of research on RSCM. The framework is developed from a chain perspective taking into consideration the interactions between forward and reverse chains as well as those among the chain members. This study also discusses the meanings and focus of various definitions of RSCM, leading to developing a definition of RSCM that reflects its overall concept. This study also briefly discusses the continuing research direction and a plan based on this paper to validate and improve the proposed framework.

\section{Problem description and formulation}

The supply chain under study here is composed of supplier, manufacturer, and customers. The backward information flow in this supply chain (SC) is from customers to other layers. Collecting customers' opinions and mining their requirements are considered as essential component of this research model. The customers' opinions are in three parts of transportation, production and quality. Using a k-means clustering technique, the opinions are classified and then using a mathematical program we present an approach to fulfill customers' needs. The definitions of indices, parameters and decision variables employed for mathematical formulation are as follows:

\section{Indices:}

$i$ : Index for factors in the third category (customer relationship costs)

$j:$ Index for factors in the second category (competitive price) 
$k$ : Index for factors in the first category (product variety)

l: Customers' opinions collection method (manually distributing questionnaires, SMS, web, fax)

Parameters:

$C_{k}$ : Process capability for $k$ factor

$h_{k}$ : Cost of needed items to run for $k$ factor

$B$ : Total cost available to the required items

$\mathrm{Co}_{j}$ : operating costs for $j$ factor

$Q_{j}$ : The number of sales with respect to the $j$ factor

$\theta$ : Profit margins

$W_{j}$ : The maximum price that the customer is willing to pay for each factor $j$

$S_{i l}$ : Operating labor cost $i$ getting through of $l$ method

$F_{i l}$ : Factor IT Costs $i$ getting through of $l$ method

$V_{i l}$ : Speed of the poll $i$ factor getting through of $l$ method

$n_{i l}:$ Number of acquired factor $i$ getting through of $l$ method

$t_{i l}$ : When using the comments we have $l$ method for $i$ factor

$u s l_{k}$ : Upper control limit for the $k$ factor

$I s l_{k}$ : Lower control limit for the $k$ factor

Decision variables:

$Z_{i l}$ : If the $\mathrm{i}^{\text {th }}$ factor from the poll cost category taken from the $1^{\text {th }}$ poll method is chosen, 1 otherwise zero.

$y_{j}$ : if the $\mathrm{j}^{\text {th }}$ factor from the competitive cost category is chosen, 1 , otherwise zero.

$x_{k}$ : if the $\mathrm{k}^{\text {th }}$ factor from the product diversification category is chosen, 1 , otherwise zero.

$p r_{j}$ : if the $\mathrm{k}^{\text {th }}$ factor from the product diversification category is chosen, 1 and otherwise zero. The product cost is chosen according to $\mathrm{j}^{\text {th }}$ factor.

Proposed mathematical model

The objective function of product diversification is defined as follows, $\max Z=\sum_{k} c_{k} \cdot x_{k}$ 
The primary purpose of the objective function of product diversification is to maximize the total capability of processes of the chosen factors in the category of product diversification.

$\sum_{k} x_{k} \geq 1$

Constraint (2) indicates that at least one of the factors of this category (product diversification) should get the value of 1 .

$\sum_{k} h_{k} \cdot x_{k} \leq B$

Constraint (3) indicates that the total cost of the necessary items to run on the $\mathrm{k}^{\text {th }}$ factor, should be less than the total available cost for the required items.

$x_{k} \in\{0,1\}$

Constraint (4) indicates that if the $\mathrm{k}^{\text {th }}$ factor from the product diversification category is chosen, 1 otherwise zero.

$c_{k}=\frac{u s l_{k}-l s l_{k}}{6 \delta_{k}}$

Process capability index, is calculated from the above formula:

- If $c_{p}>1$, the process can observe the limitation of acceptable characteristics.

- If $c_{p}=1$, the process nearly can observe the limitation of acceptable characteristics.

- If $c_{p}<1$, the process can't observe the limitation of acceptable characteristics.

The objective function of competitive price is as follows,

$\max \sum_{j} y_{j}\left(\operatorname{Pr}_{j} \cdot Q_{j}\right)-c o_{j}$

The goal of the objective function of competitive price is to maximize the profit that comes from multiplying the product selling price according to $\mathrm{j}^{\mathrm{th}}$ factor to the number of product sales according the $\mathrm{j}^{\text {th }}$ factor minus factor costs.

$\theta \sum_{j} c o_{j} \leq p r_{j}$

Constraints (7) indicates the maximum benefit that manufacturer can take from the customer, in costs; the profit margin should be less than the product price.

$\sum_{j} y_{j} \cdot w_{j} \geq p r_{j}$

Constraint (8) indicates that the product price must be less than the maximum price that the customer tends to pay for each factor of $j$.

$y_{j} \in\{0,1\}$.

Constraint (9) indicates that if the $\mathrm{j}^{\text {th }}$ factor from the competitive price category is chosen 1 , and otherwise zero.

$\sum_{j} y_{j} \geq 1$

$p r_{j} \geq 0$ 
Constraint 11 indicates that the product price is positive.

$p r_{j} \leq M \cdot y_{j} \quad \forall j$,

Objective function of poll cost:

$\min \sum_{i} \sum_{l} Z_{i l} \cdot\left(S_{i l}+F_{i l}\right)$

The purpose of objective function of poll cost is minimize the total cost (total cost of technology and human resources),

$\max \sum_{i} \sum_{l} V_{i l} \cdot Z_{i l}$

The purpose of objective function of poll cost is maximize the poll speed that achieves from different methods:

$V_{i l}=\sum_{i} \frac{n_{i l}}{t_{i l}} \quad \forall l$

Poll speed that resulting from dividing the number of comments on time.

$Z_{i l} \in\{0,1\}$

$\sum_{i} \sum_{l} Z_{i l} \geq 1$

Constraint (16) indicates that if $\mathrm{i}^{\text {th }}$ factor from the poll cost category that taken from the $1^{\text {th }}$ poll method is chosen, 1 otherwise zero.

\section{Linearization of the objective function}

Nore that the nonlinear equation given in Eq. (6) can be linearized by using the inequality specified in Eq.(12), where $M$ is a sufficiently large number; since $y_{j}$ is equal to 0 or 1 and Eq. (6) implies that $\operatorname{Pr}_{j}$ is 0 (when $y_{j}=0$ ) or arbitrary (when $y_{j}=1$ ). The latter is imposed when $M$ is large enough, and the former is guaranteed by the simultaneous incurred inequalities $p r_{j} \leq 0$ and $p r_{j} \geq 0$ (from Eq. (11)).

\section{Case study}

Poll of customers in several ways

Considering the demographic of the area in the 1000 Customer Comments, here we acquire the comment from for different methods: Hand questionnaire, a short message (sms), Web, fax.

From the 1000 poll:

- 150 cases are Hand questionnaire $(1=1)$

- 450 cases are short message ( $\mathrm{sms})(\mathrm{l}=2)$

- 350 cases are web $(1=3)$

- 100 cases are $\operatorname{Fax}(l=4)$

\section{Sampling by using STRATA method}

By using STRATA method, we consider 100 customers for getting decision. The sampling is done by STRATA method that explained as follows, 
Sample size for method $l$

Total population size

STRATA sampling for this problem we have N=1000 n=100 $\quad N_{1}$

$n_{1}=\frac{150}{1000} \times 100=15, n_{2}=\frac{450}{1000} \times 100=45, n_{3}=\frac{350}{1000} \times 100=35, n_{4}=\frac{100}{1000} \times 100=10$

Average factors weight

After STRATA sampling we calculate the average weight of every sixteen factors separately:

Average weight for every sixteen factors respectively from left to right:

$3.33,3.52,3.84,3.49,3.17,3.69,3.38,3.15,4.02,3.99,3.05,3.72,3.70,3.95,63.65,3.25$

\section{K-Means Algorithm:}

K-means (MacQueen, 1967) is one of the simplest unsupervised learning algorithms, which solve some well-known clustering problems. The procedure follows a simple and easy way to classify a given data set through a certain number of clusters (assume k clusters) fixed a priori. The main idea is to consider $k$ centroids, one for each cluster. These centroids should be placed in a cunning way because various locations cause different results. So, a better choice is to place them as much as possible far away from each other. The next step is to take each point belonging to a given data set and associate it to the nearest centroid. When no point is pending, the first step is completed and an early group age is performed. At this point we need to re-calculate $\mathrm{k}$ new centroids as bar centers of the clusters resulting from the previous step. After we have these $k$ new centroids, a new binding has to be applied among the same data set points and the nearest new centroid. A loop has been generated. As a result of this loop we may notice that the $k$ centroids change their location step by step until no more changes are done. In other words centroids do not move any more.

Finally, this algorithm aims at minimizing an objective function, in this case a squared error function. The objective function

$J=\sum_{j=1}^{k} \sum_{i=1}^{n}\left\|x_{i}^{(j)}-c_{j}\right\|^{2}$,

where $\left\|x_{i}^{(j)}-c_{j}\right\|^{2}$ is a chosen distance measure between a data point $x_{i}^{(j)}$ and the cluster centre $c_{j}$, is an indicator of the distance of the $n$ data points from their respective cluster centers.

The algorithm is composed of the following steps:

1. Place $K$ points into the space represented by the objects that are being clustered. These points represent initial group centroids.

2. Assign each object to the group that has the closest centroid.

3. When all objects have been assigned, recalculate the positions of the K centroids.

4. Repeat Steps 2 and 3 until the centroids no longer move. This produces a separation of the objects into groups from which the metric to be minimized can be calculated. 
Although it can be proved that the procedure will always terminate, the k-means algorithm does not necessarily find the most efficient configuration, corresponding to the global objective function minimum. The algorithm is also significantly sensitive to the initial randomly selected cluster centres. The k-means algorithm can be run multiple times to reduce this effect. In this paper, we cluster 16 factors and distribute customers' comments among them based on three categories mentioned earlier. Three random points that we picked up for three clusters respectively from right to left are:

$3.28=$ first cluster (product variation)

$3.42=$ second cluster (competitive price)

$3.61=$ third cluster (comments following)

We coding K-means algorithm in MATLAB software (MATLAB code for K-means algorithm is in the appendix). Here are the results:

Results of k-means algorithm

The centers of obtained clusters:

The First Cluster Center Is: 3.1550

The Second Cluster Center Is: 3.4300

The Third Cluster Center Is: 3.8200

Clustering performed for the first category Clustering performed for the second category (product variation): (competitive price):

The First Cluster is: 3.17

The Second Cluster is: 3.33

The First Cluster is: 3.15

The First Cluster is: 3.05

The First Cluster is: 3.25

The Second Cluster is: 3.52

The Second Cluster is: 3.49

The Second Cluster is: 3.38

Clustering performed for the third category (comments following):

The Third Cluster is: 3.84

The Third Cluster is: 3.69

The Third Cluster is: 4.02

The Third Cluster is: 3.99
The Third Cluster is: 3.72

The Third Cluster is: 3.70

The Third Cluster is: 3.95

The Third Cluster is: 3.65

Here are the factors that placed in the first cluster (product variation):

1. Warranty

2. Effectiveness

3. Damages resulting from delay

4. Deterioration of handling

Here are the factors that placed in the second cluster (competitive price):

1. Proper packaging

2. Quality compared to competitors

3. Apparent quality of the product,

4. Inspection

Here are the factors that placed in the third cluster (comments following):

1. Services

2. Desired performance 
3. Efficiency

4. Labor productivity

5. Being fresh

6. Provide services in all areas

7. Order online

8. Availability

We code and run every of our three objective function separately in lingo software.

Calculation and determination of the mathematical model parameters:

- Process Capability values

$$
\mathrm{c}_{1}=1.2, \mathrm{c}_{2}=1.6, \mathrm{c}_{3}=1, \mathrm{c}_{4}=1.4
$$

- The values of costs required for running on $k^{\text {th }}$ factor

$$
h_{1}=5, h_{2}=6, h_{3}=8, h_{4}=7
$$

- The total available cost for required stuff

$$
\mathrm{B}=17
$$

- Total product sale according to $\mathrm{j}^{\text {th }}$ factor

- Costs of $\mathrm{j}^{\text {th }}$ factor

$$
Q_{1}=50, Q_{2}=40, Q_{3}=38, Q_{4}=44
$$

$$
\mathrm{CO}_{1}=6, \mathrm{CO}_{2}=7, \mathrm{CO}_{3}=10, \mathrm{CO}_{4}=5
$$

- The maximum price that the customer is willing to pay according to each of the factor $\mathrm{j}^{\text {th }}$

- The profit margin

$$
W_{1}=8, W_{2}=10, W_{3}=13, W_{4}=9
$$

- Labor cost matrix for each I and 1:

$$
\mathrm{s}=\left[\begin{array}{llll}
5 & 6 & 5 & 7 \\
5 & 6 & 7 & 6 \\
6 & 9 & 6 & 7 \\
5 & 7 & 7 & 5 \\
7 & 6 & 5 & 8 \\
5 & 9 & 7 & 5 \\
5 & 6 & 8 & 5 \\
9 & 6 & 7 & 8
\end{array}\right]
$$

$$
\theta=1.15
$$

- IT cost matrix for each I and 1:

$$
\mathrm{f}=\left[\begin{array}{llll}
5 & 7 & 6 & 9 \\
5 & 7 & 7 & 9 \\
5 & 6 & 9 & 5 \\
6 & 7 & 5 & 9 \\
9 & 8 & 7 & 9 \\
5 & 7 & 5 & 9 \\
5 & 6 & 9 & 6 \\
5 & 6 & 9 & 8
\end{array}\right]
$$

Using AHP for multi-objective optimization

For optimizing the second objective function of the problem statement, we use the weighting method to objective function by means of analytic hierarchy process. We compare two objective functions in terms of three criteria including competitive advantage, economical aspect and strategic perspective. The results will be in Table 1. Matrix of binary comparison of objective- the criteria is based on Table 1:

Table 1

The objective-criteria matrix

strategic perspective economical aspect competitive advantage

First Objective function $\quad 0.557$

Second Objective function 0.443

0.639
0.361
0.488

0.512

- Poll speed matrix for each I and 1 : $\begin{array}{llll}18.0 & 40.2 & 21.6 & 6.0\end{array}$

$\begin{array}{llll}19.8 & 32.4 & 19.8 & 15.0\end{array}$

$\begin{array}{llll}12.0 & 36.0 & 30.0 & 30.0\end{array}$

$\begin{array}{llll}19.8 & 24.0 & 18.0 & 19.8\end{array}$ 
Criteria binary comparison- criteria is based on Table 2:

Table 2

Pairwise comparison

\begin{tabular}{lcccc}
\hline & strategic perspective & economical aspect & competitive advantage & W \\
\hline strategic perspective & 1 & 3 & 2 & 0.503 \\
economical aspect & $1 / 3$ & 1 & 5 & 0.348 \\
\hline competitive advantage & $1 / 2$ & $1 / 5$ & 1 & 0.149 \\
\hline
\end{tabular}

$\psi_{1}=$ Total weight for objective $1=0.557 \times 0.503+0.639 \times 0.348+0.488 \times 0.149=0.575$

$\psi_{2}=$ Total weight for objective $2=0.443 \times 0.503+0.361 \times 0.348+0.512 \times 0.149=0.425$

New Objective function for the comments following category:

$$
\max \left(\psi_{1}\left(\sum_{i} \sum_{l} V_{i l} Z_{i l}\right)-\psi_{2}\left(\sum_{i} \sum_{l} Z_{i l} \cdot\left(S_{i l}+F_{i l}\right)\right)\right)
$$

\section{Mathematical model results}

Objective function of product variation:

After solving the model by lingo software:

- The value of Objective function of product variation became 3 .

- The deterioration and effectiveness due to displacement factors, got the value of 1 , this means that in the category of product variation, the two factors of deterioration and effectiveness due to displacement are effective.

$$
x_{2}=1, x_{4}=1
$$

The objective function of competitive price:

After solving the model by lingo software:

- The value of the Objective function of product variation became 1662 .

- The value of product price according to $\mathrm{j}$ 'th factor:

$$
\mathrm{pr}_{1}=8, \mathrm{pr}_{2}=10, \mathrm{pr}_{3}=13, \mathrm{pr}_{4}=9
$$

The objective function of comments following:

After solving by lingo software the value of objective function became 39.15.

Here is the factor that got the value of 1 in this category that means that they are effective:

$$
\begin{gathered}
z_{12}=1, z_{13}=1, z_{22}=1, z_{32}=1, z_{34}=1, z_{42}=1, z_{52}=1, z_{53}=1, z_{61}=1, \\
z_{62}=1, z_{72}=1, z_{73}=1, z_{74}=1, z_{82}=1
\end{gathered}
$$

\section{Conclusions}

In this article, we examined the issue of reverse supply chain, considering customer requirements. The proposed model considered supply chain with three layers of supplier, manufacturer and customer. In customers' layer, the proposed model performed data mining based on customers' 
comments to identify and to fulfill their requests. First by preparing a list of customers comments, we have collected their opinions in cases that we need, in here we assumed to evaluate the customers comments in three categories of transportation, production and quality. Then by using K-means algorithm, that is data mining technique, we have performed the clustering to categorize the data based on their characteristics. By doing this, we could identify the customers' requests and eventually fulfilled them. We have also considered the factors in each category, developed a mathematical model for each category, and eventually by using of lingo software we have solved and presented the results.

The proposal for future works:

- In customers' satisfactory issue, the operational field of geographical servicing by using positioning and allocation models can be considered.

- The considered data in this model are deterministic, while the uncertain data with fuzzy and probabilistic approach can be considered in the modeling.

- In this article we used K-means algorithm, while for more efficiency, in large volume data, the algorithms based on artificial intelligence can be used.

- In one of the models we used the multi objective weighting algorithm, that one can use the methods such as ideal planning or adoption planning.

\section{References}

Blackburn, J. D., Guide, V. D. R., Souza, G. C., \& Van Wassenhove, L. N. (2004). Reverse supply chains for commercial returns. California Management Review, 46(2), 6-22.

Daniel, V., Guide Jr, R., \& Jayaraman, V. (2000). Product acquisition management: current industry practice and a proposed framework. International Journal of Production Research, 38(16), 37793800 .

Dowlatshahi, S. (2000). Developing a theory of reverse logistics. Interfaces, 30(3), 143-155.

Guide, V. D. R. (2000). Production planning and control for remanufacturing: industry practice and research needs. Journal of Operations Management,18(4), 467-483.

Guide, V. D. R., Jayaraman, V., Srivastava, R., \& Benton, W. C. (2000). Supply-chain management for recoverable manufacturing systems. Interfaces,30(3), 125-142.

Guide Jr., D. \& Van Wassenhove, L. (2002). The reverse supply chain. Harvard Business Review, 2526.

Guide, V. D. R., Jayaraman, V., \& Linton, J. D. (2003). Building contingency planning for closedloop supply chains with product recovery. Journal of operations Management, 21(3), 259-279.

Guide Jr, V. D., \& Pentico, D. (2003). A hierarchical decision model for re-manufacturing and reuse. International Journal of Logistics, 6(1-2), 29-35.

Guide, V. D. R., Teunter, R. H., \& Van Wassenhove, L. N. (2003). Matching demand and supply to maximize profits from remanufacturing. Manufacturing \& Service Operations Management, 5(4), 303-316.

Guide, V. D. R., \& Van Wassenhove, L. N. (2003). Closed-loop supply chains: practice and potential. Interfaces, 33(6), 1-2.

Guide, V. D. R., Harrison, T. P., \& Van Wassenhove, L. N. (2003). The challenge of closed-loop supply chains. Interfaces, 33(6), 3-6.

Lee, J. E., Gen, M., \& Rhee, K. G. (2009). Network model and optimization of reverse logistics by hybrid genetic algorithm. Computers \& Industrial Engineering, 56(3), 951-964.

Lu, Z., \& Bostel, N. (2007). A facility location model for logistics systems including reverse flows: The case of remanufacturing activities. Computers \& Operations Research, 34(2), 299-323.

Krikke, H., Blanc, I. \& van de Velde, S. (2004). Product modularity and the design of closed-loop supply chains. California Management Review, 46(2), (2004), 23-39. 
Minner, S. (2001). Strategic safety stocks in reverse logistics supply chains. International journal of production economics, 71(1), 417-428.

Pishvaee, M. S., Farahani, R. Z., \& Dullaert, W. (2010). A memetic algorithm for bi-objective integrated forward/reverse logistics network design. Computers \& Operations Research, 37(6), $1100-1112$.

Rogers, D. S., \& Tibben-Lembke, R. (2001). An examination of reverse logistics practices. Journal of business Logistics, 22(2), 129-148.

Tibben-Lembke, R. S. (2004). Strategic use of the secondary market for retail consumer goods. California Management Review, 46(2), 90-104.

Van Nunen, J. A., \& Zuidwijk, R. A. (2004). E-enabled closed-loop supply chains. California Management Review, 46(2), 40-54. 